\title{
Reinventing the square wheel
}

Many of us have watched in disbelief as our friends and colleagues in the UK National Health Service (NHS) have had their clinical autonomy and professionalism eroded. Managers and purchasers of healthcare now tell UK ENT surgeons which procedures they can and cannot perform and, to a limited extent, on whom they can perform them. Adenotonsillectomy is now regarded as a 'procedure of limited clinical value', and the number of tonsillectomies performed in the NHS has plummeted. Perhaps not surprisingly, the number of acute admissions for acute tonsillitis has now significantly increased, and the cost to society has undoubtedly risen substantially. Whilst you might think that the UK private sector would have been protected, BUPA has now followed suit: even with private health insurance, cover is only applied to those diseases and procedures that are deemed worthwhile. For example, my poor niece, with grade 4 tonsils and sleep-disordered breathing, cannot have either a public or private adenotonsillectomy even though the family has private insurance.

Australian healthcare seems to have been invaded by a large number of former NHS managers who are now seeking to implement similar changes on our public ENT services. If successful, the private sector will surely follow closely behind - as has been the case in the UK. The global financial crisis and drop in mining revenue has thrown public health budgets into chaos in most States and Territories. In South Australia, we are now being audited by management for our tonsillectomy listings. At ASOHNS this year, we heard Anthony Narula present compelling quality of life data backing up tonsillectomy as a valid procedure. The problem is that, in the UK, it is already too late.

With regards to cost-effectiveness, we actually have little published evidence to support expensive Australian ENT interventions. As such, we are relatively ill prepared for the management onslaught I believe is about to happen. Sleep surgery and tonsillectomy have already been put under the spotlight, and grommets, septoplasty, rhinoplasty, sinus surgery and others will probably be next. With regards to costeffectiveness, there is nothing to support expensive and time-consuming interventions such as trans-oral robotic surgery, endoscopic skull-base procedures or even a long Draf III sinus procedure.

The advantage of ASOHNS having its own publication is that research investigating Australian ENT outcomes can be published relatively rapidly. As editor, I would be extremely supportive of research assessing the quality of live benefit and cost-effectiveness of what we do. That research can then be used to defend what I believe to be safe and efficient clinical practices, which are currently under threat and which, once lost, are unlikely to be regained.

A SIMON CARNEY

ASOHNS Supplement Editor simoncarney@me.com 